\title{
Left Ventricular Longitudinal Strain Echocardiogram and Handgrip: A Useful Tool for Detecting Ischemia in the Emergency Room
}

\author{
Ecocardiograma com Strain Longitudinal do Ventrículo Esquerdo e Handgrip: Ferramenta Útil na Sala de \\ Emergência para Detecção de Isquemia
}

\author{
Ana Paula Torres Guimarães de Freitas, Natalia Marcusso Massoni, Rodrigo Bellio de Mattos Barretto \\ Dante Pazzanese Cardiology Institute
}

\section{Introduction}

Acute coronary syndrome is among the greatest diagnostic challenges for emergency room physicians. Non-invasive imaging tests such as echocardiography $(\mathrm{ECHO})$ are useful in the etiological diagnosis of chest pain. In cases of suspected ischemia, when electrocardiography (ECG) and myocardial necrosis markers (MNM) are inconclusive, ECHO can be performed at the time of pain or immediately after. ${ }^{1}$ The use of advanced techniques such as myocardial deformation analysis (strain) provides greater accuracy in identifying the coronary artery disease territory. ${ }^{2}$

This report describes a case of a patient with chest pain without segmental changes on initial $\mathrm{ECHO}$ in the emergency room. Significant coronary artery disease (CAD) changes were evident on additional tools (handgrip, strain, and postsystolic peak) as showed on the subsequent coronary angiography.

\section{Case report}

A 49-year-old hypertensive man with a family history of early CAD was admitted to the emergency room with tight chest pain at rest that had started one day prior. ECG showed sinus rhythm and negative $\mathrm{T}$ waves in $\mathrm{V} 2$ and $\mathrm{V} 3$, a sign compatible with subepicardial ischemia in the anteroseptal wall (Figure 1A).

Bedside ECHO showed normal-sized cardiac cavities and preserved left ventricular (LV) myocardial contractility, an LV ejection fraction (LVEF) of 63\% (Simpson's method), and an LV global longitudinal strain (GLS) at rest of $-197 \%$ with a reference value $\leq-18 \%$ (Figure $2 \mathrm{~A}$ ). After the handgrip maneuver, LV dilatation, hypocontractility of the apical segments and anteroseptal wall, and a GLS decrease to $-12.8 \%$ were noted, with greater involvement in the hypocontractile segments and the presence of post-systolic contraction (Figures 2B and 3).

Coronary angiography showed a $70 \%$ obstructive lesion in the proximal third of the anterior descending coronary artery, which was treated with a pharmacological stent (Figure 1B).

\section{Keywords}

Chest Pain, Echocardiography, Strain, Emergencies.

Mailing Address: Ana Paula Torres Guimarães de Freitas •

E-mail: ap_freitas4@hotmail.com

Manuscript received 7/24/2021; revised 10/17/2021; accepted 10/29/2021

DOI: $10.47593 / 2675-312 X / 20213404$ eabc238

\section{Discussion}

In the context of chest pain, a resting $\mathrm{ECHO}$ allows the assessment of the heart structure, segmental and global function of the ventricles, cavity size, valve anatomy, and pathologies that justify the patient's symptoms, including pericardial effusion, hypertrophic cardiomyopathy, aortic stenosis, aortic dissection, deficient segmental changes, and others. ${ }^{3}$

Ischemia is diagnosed by $\mathrm{ECHO}$ through segmental contractility analysis. However, the method has limitations when used alone, mainly since it is examiner-dependent, which requires experience to ensure a more accurate diagnosis. ${ }^{3}$ Therefore, the 2020 European guideline for acute coronary syndrome without ST-segment elevation suggests the use of $\mathrm{ECHO}$ associated with more accurate techniques such as speckle tracking for the diagnosis of ischemia in stable patients, with non-diagnostic ECG, negative MNM, and the absence of regional contractility disorders, as it presents high sensitivity and specificity for the test (86\% and $73 \%$, respectively, for GLS values < $-18.8 \%$ - recommendation class I, evidence level B). ${ }^{2}$

The analysis of strain by ECHO is used as a quantitative method for diagnosing ischemia, as it assesses the muscle fiber deformation of each segment, which is arranged into three layers: subepicardial, mesocardial, and subendocardial. The fibers of the subendocardial layer, the most susceptible to ischemia, are arranged longitudinally, so the GLS here is expected to be the most sensitive for the evaluation of ischemic segments as it is the first to change..$^{1,3,4}$ In addition, strain on $\mathrm{ECHO}$ can be a marker of myocardial fibrosis, enabling the diagnosis of post-ischemic myocardial scarring. ${ }^{4}$ The 2019 positioning on $\mathrm{ECHO}$ indications for adults suggests GLS calculation using the existing diagnostic algorithms and risk classification in patients with suspected coronary disease as recommendation class Ila, evidence level B. ${ }^{5}$

In addition to the peak systolic value of the strain, evaluation of the post-systolic contraction peak, consisting of continued contraction of the myocardium after aortic valve closure, is also used. This finding is frequent in conduction disorders or regional myocardial dysfunction, especially in myocardial ischemia or stunned myocardium. It is rarely found in healthy people, but with a low magnitude and preserved GLS. ${ }^{6}$

Postsystolic contraction occurs in the isovolumetric relaxation phase, a metabolically active process dependent on energy use. An ischemic myocardium presents incompatibility between reduced production and increased energy consumption, with overlapping of the late systolic contraction and isovolumetric 


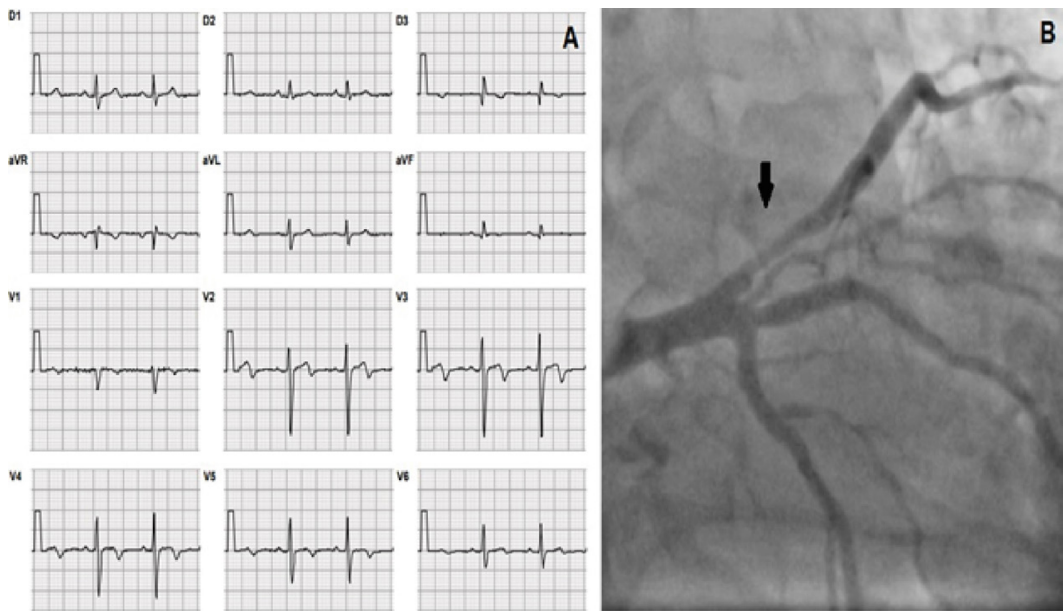

Figure 1-A: Electrocardiogram taken on admission. B: Coronary angiography showing a 70\% obstructive lesion in the in the proximal third of the left anterior descending artery (arrow).

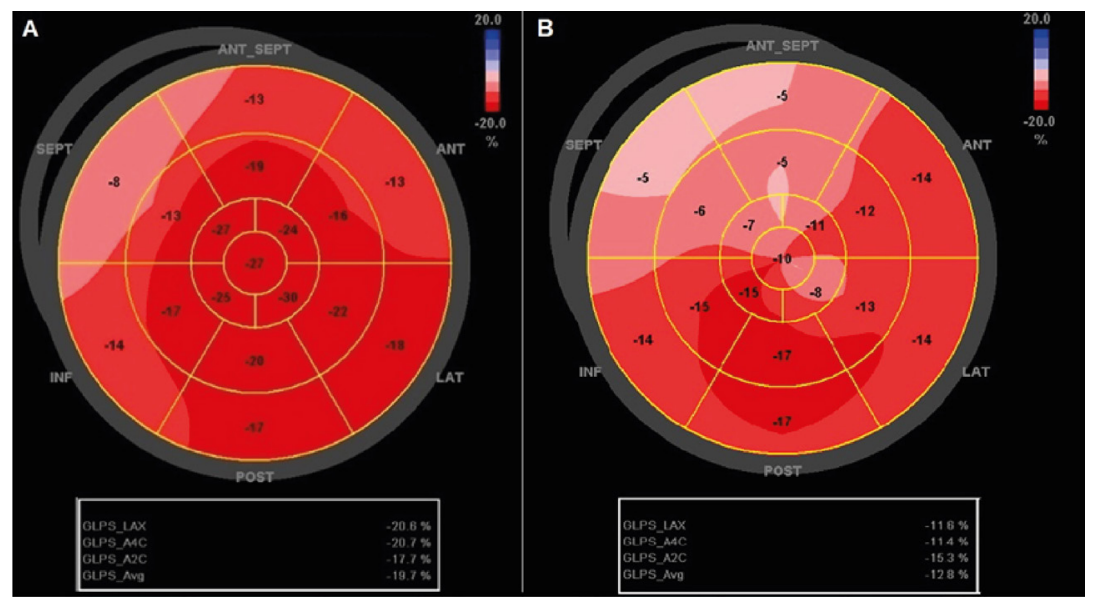

Figure 2 - A: Initial left ventricular global longitudinal strain showing preserved values. B Left ventricular global longitudinal strain after handgrip maneuver showing reduced values and better definition of the coronary territory of the anterior descending artery.

relaxation. Therefore, strain curve analysis associated with other post-processing findings improves the diagnosis of CAD. ${ }^{6}$

In acute coronary syndrome, the strain is highly feasible and quick to determine, and it can be done before coronary angiography to aid in more questionable cases of severe lesions, enabling greater diagnostic accuracy and the identification of patients who can benefit from reperfusion therapy. The test can also exclude major coronary lesions in patients with non-diagnostic ECG findings and negative biomarkers. ${ }^{1}$ The literature also showed that GLS is a better predictor of adverse cardiovascular events in old infarcts than the LVEF and LV wall motion score index. ${ }^{7}$

Stress ECHO aims to diagnose obstructive lesions with hemodynamic repercussions when the myocardium is subjected to stress, whether physical or pharmacological, with dobutamine being the most commonly used drug in clinical practice. ${ }^{3,8}$ By increasing heart rate $(\mathrm{HR})$, inotropism, and oxygen demand, hypoperfused areas of the myocardium become hypocontractile. The method has an established role in chest pain patients with a low probability of acute CAD after an observation period without ECG and marker changes, which also have a prognostic role in the evaluation of ventricular function at rest and under stress, cavity dilation, development of dysfunction diastolic, right ventricular dysfunction etc. ${ }^{4}$

The handgrip is a safe complementary technique to dobutamine stress $\mathrm{ECHO}$ that can also help diagnose ischemia. Simple to perform, it consists of isometric muscle contraction and increases systolic blood pressure and HR through increased peripheral vascular resistance and sympathetic nervous system activation. ${ }^{8,9}$ In CAD, such hemodynamic 


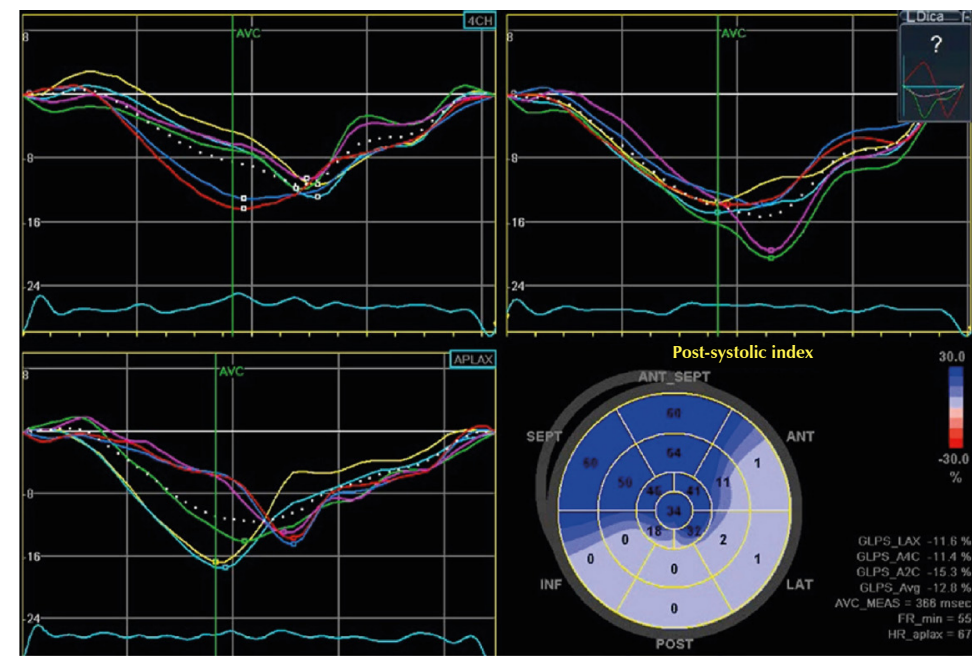

Figure 3 - Left ventricular global longitudinal strain demonstrating the late post-systolic peak.

changes increase the myocardial oxygen requirement and can induce ischemia if the coronary flow reserve is reduced. Therefore, the handgrip test can be associated with diagnostic methods for ischemia. ${ }^{10}$

Data on handgrip applicability in the context of emergency chest pain and on strain evaluation during the maneuver are scarce in the literature. Some studies show discrepancies in the method's sensitivity when associated with pharmacological stress. Protocols using handgrip associated with a vasodilator pharmacological stressor with $50 \%$ of the maximum grip strength resulted in an increase of $25 \%$ in the method's sensitivity, while using $25 \%$ of the maximum strength resulted in a $7 \%$ sensitivity increase. ${ }^{10}$

The use of handgrip alone is not routine in our emergency room service. However, its practical performance and confirmation with the deformation measures enables a safe diagnosis and quick referral to interventional treatment.

\section{References}

1. Nicolau JC, Feitosa Filho GS, Petriz JL, Furtado RH, Précoma DB, Lemke W, etal. Diretrizes da Sociedade Brasileira de Cardiologia sobre Angina Instável e Infarto Agudo do Miocárdio sem Supradesnível do Segmento ST - 2021. Arq Bras Cardiol. 2021;117(1):181-264.

2. Collet JP, Thiele H, Barbato E, Barthélémy O, Bauersachs J, Bhatt DL, et al.; ESC Scientific Document Group. 2020 ESC Guidelines for the management of acute coronary syndromes in patients presenting without persistent ST-segment elevation. Eur Heart J. 2021;42(14):1289-1367. doi: 10.1093/eurheartj/ ehaa575. Erratum in: Eur HeartJ. 2021;42(19):1908. Erratum in: Eur HeartJ. 2021;42(19):1925. Erratum in: Eur HeartJ. 2021 May 13;: PMID: 32860058

3. Pellikka PA, Arruda-Olson A, Chaudhry FA, Chen MH, Marshall JE, Porter TR, et al. Guidelines for Performance, Interpretation, and Application of Stress Echocardiography in Ischemic Heart Disease: From the American Society of Echocardiography. J Am Soc Echocardiogr. 2020;33(1):1-41.e8. doi: 10.1016/j.echo.2019.07.001

4. Pastore MC, Mandoli GE, Contorni F, Cavigli L, Focardi M, D'Ascenzi F, et al. Speckle tracking echocardiography: early predictor of diagnosis and
Therefore, the incorporation of this technique associated with strain variables may improve diagnosis due to its early implementation on emergency room admission and relevant information for managing this patient profile.

\section{Authors' contributions}

Research conception and design: Barretto RBM, Freitas APTG, Massoni NM; data collection: Freitas APTG, Massoni NM; manuscript writing: Freitas APTG, Massoni NM; critical review of the manuscript for important intellectual content: Barretto RBM.

\section{Conflict of interest}

The authors have declared that they have no conflict of interest.

prognosis in coronary artery disease. Biomed Res Int. 2021;2021:6685378. doi: $10.1155 / 2021 / 6685378$

5. Barberato SH, Romano MM, BeckAL, Rodrigues AC, Almeida AL, Assunção BM et al. Position Statement on Indications of Echocardiography in Adults - 2019. Arq Bras Cardiol. 2019 Aug 8;113(1):135-181. doi: 10.5935/abc.20190129

6. Belohlavek M. Post-systolic shortening: a functional window into ischemic memory? JACC Cardiovasc Imaging. 2012;5(1):12-4. doi: 10.1016/j. jcmg.2011.09.014

7. Almeida AL, Gjesdal O, Mewton N, Choi EY, Teixido-Tura G, Yoneyama K, et al Speckle-tracking pela ecocardiografia bidimensional - aplicações clínicas. Rev Bras Ecocardiogr Imagem Cardiovasc. 2013;26(1):38-49.

8. Afridi I, Main ML, Parrish DL, Kizilbash A, Levine BD, Grayburn PA Usefulness of isometric hand grip exercise in detecting coronary artery disease during dobutamine atropine stress echocardiography in patients with either stable angina pectoris or another type of positive stress test. Am J Cardiol. 1998;82(5):564-8. doi: 10.1016/s0002-9149(98)00398-1 
Freitas et al.

Left Ventricular Longitudinal Strain Echocardiogram and Handgrip

\section{Case Report}

9. Minardi G, Zampi G, Pergolini A, Pero G, Moschella Orsini F. Chest pain caused by myocardial ischemia or not: sometimes the old handgrip test can solve the dilemma. Can J Cardiol. 2012;28(4):515.e7-9. doi: 10.1016/j. cjca.2011.12.007
10. Tawa CB, Baker WB, Kleiman NS, Trakhtenbroit A, Desir R, Zoghbi WA. Comparison of adenosine echocardiography, with and without isometric handgrip, to exercise echocardiography in the detection of ischemia in patients with coronary artery disease. J Am Soc Echocardiogr. 1996;9(1):3343. doi: 10.1016/s0894-7317(96)90102-9 